\title{
EARLY RESULTS OF TOTAL ENDOSCOPIC CLOSURE FOR ATRIAL SEPTAL DEFECT IN CHILDREN AT CARDIOVASCULAR CENTER, E HOSPITAL, HANOI, VIET NAM
}

\author{
Nguyen Ba Phong ${ }^{1}$, Do Anh Tien ${ }^{1,2}$, Le Ngoc Minh ${ }^{1}$, Tran Thuy Nguyen ${ }^{1,2 *}$, \\ Luu Phuong Linh ${ }^{1}$, Luong Thi Nhu Huyen ${ }^{1}$, Le Ngoc Thanh ${ }^{1,2}$
}

\section{ABSTRACT}

Introduction: Atrial Septal Defect is the most common congenital heart disease. Minimally invasive cardiac surgery is being perfomed routinely at several cardiovascular centers in Vietnam. At E Cardiovascular Center, from 2016 to 2019, we performed total endoscopic closure for atrial septal defect in children using 4 trocars. From 2020 to present, we have reduced the number of trocars to three. This report was to evaluate the effectiveness and early results of total endoscopic closure with 3 trocars for atrial septal defect in children.

Method: Twelve children underwent ASD closure from $1 / 2020$ to $5 / 2021$, with mean age of 7.7 years old (range from 2.5 to 11 ); mean weight was 20.8 kilograms (range from 12 to 40). All the patients underwent the operation with peripheral cardiopulmonary bypass (CPB).

Result: The mean peripheral circulation time was 70 minutes (range from 56 to 100 minutes) on beating hearts. There were 8 cases with patch-closure and 4 cases with directclosure. After operations, we reexamined by echocardiography, the atrial septal defects were closed completely with no residual shunt, the common femoral arteries at the cannula position were normal and no stenosis were present.

Conclusion: Totally endoscopic closure for ASD on beating hearts with 3 trocars is save with a very good short-term results.

Keywords: Atrial Septal Defect, Minimally invasive cardiac surgery

\section{INTRODUCTION}

ASD is the most common congenital heart defect [1-2]. There are many surgical methods to close the ASD such as the classic surgery through median sternotomy [3], minimally invasive cardiac surgery through right small thoracotomy, assisted endoscopic cardiac surgery and the most advanced is total endoscopic cardiac surgery (without robotic assistance). Today, minimally invasive cardiac surgery to close the ASD ( including endoscopic surgery) is being applied by several cardiovascular centers in Viet nam, but mainly on adults. In Cardiovascular Center, Hospital E, Hanoi, we have been performing total endoscopic cardiac surgery to close ASD since 2016 with 4 trocars, both children and adults. Since 2020 until now, we reduce the number of trocars for operations to three. Therefore, we conducted this study to evaluate the effectiveness, safety and early results of this change in surgical procedure.

\section{METHODS}

From January 2020 to May 2021, We operated twelve patients who was diagnosed the second ASD with mean age was 7.7 year olds (range from 2.5 to 11 ); mean weight was 20.8

1 Department of Paediatric Cardiovascular Surgery, Cardiovascular Center, E Hospital

2 University of Medicine and Pharmacy, Vietnam National University Hanoi

* Corresponding author: Nguyen Tran Thuy

Email: drtranthuyvd@gmail.com

Address: E Hospital, 87-89 Tran Cung, Hanoi, Vietnam, 10000 Vietnam National University, 114 Xuan Thuy, Hanoi, Vietnam, 10000 Received: 23 June $2021 \quad$ Accepted: 05 July 2021 
kilograms (range from 12 to $40 \mathrm{~kg}$ ) (Table 1). All the patients have underwent peripheral cardiopulmonary bypass ( $\mathrm{CPB}$ ) and beating heart with filling $\mathrm{CO} 2$ in the surgery cavity.

Surgical technique: The patient lied in the left leaning position 30 degree, with endotracheal anesthesia. The anesthesis placed the central venous catheter through left internal jugular vein (IJV) and inserted a needle, which would be used for guidewire introduction for superior vena cava
( SVC) cannulation - in the right IJV.

\section{Setting up peripheral cardiopulmonary bypass (CPB)}

We used systemic doses of heparin $3 \mathrm{ml} / \mathrm{kg}$ body weight. We opened a mini incision on the right inguinal fold, revealing common femoral artery and femoral vein (for the inferior vena cava- IVC). SVC was placed through the right IJV with Seldinger technique. We tested the arterial line and the $\mathrm{CPB}$ was activated.

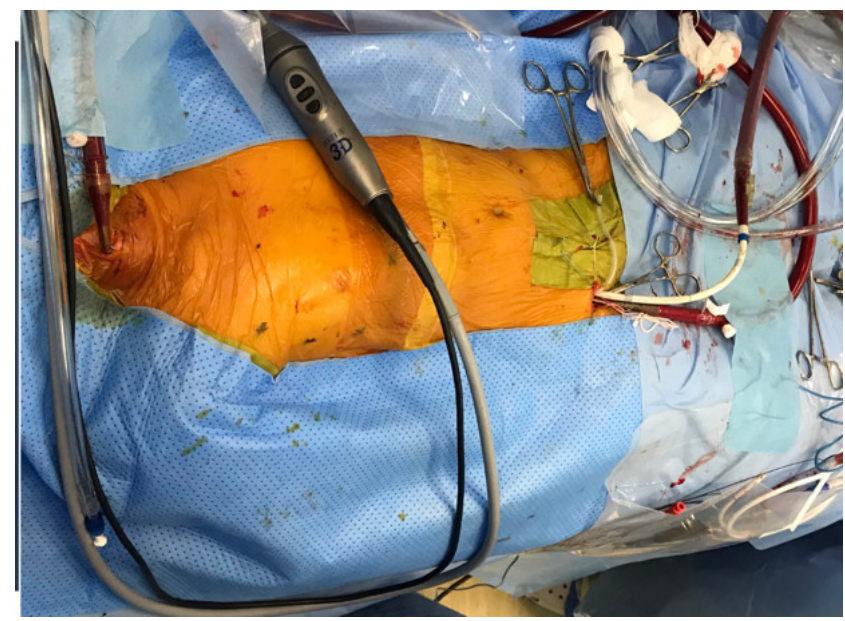

Figure 1: Peripheral cardiopulmonary bypass

Three trocars were placed in the previously marked positions. One 12-mm trocar was a main port at the sixth intercostal space in the midline collarbone. One 10-mm trocar was a camera port at the fifth intercostal space in the midaxillary line. And the last one, $5-\mathrm{mm}$ trocar was an assistance port at the fourth intercostal space in the anterior axillary line.

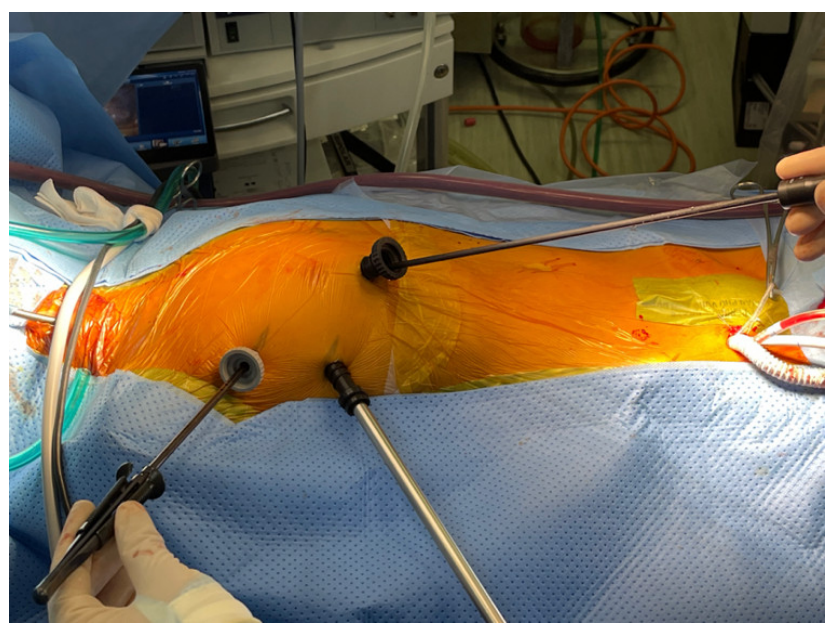

Figure 2: Three trocart's site to surgery 
After that, the pericardium was opened parallel and away $1.5 \mathrm{~cm}$ from the diaphragmatic nerve and suturing hangs to the chest wall. Then, we dissected SVC from the right pulmonary artery and snaring SVC. The pleural and pericardiac cavities were filled with $\mathrm{CO} 2$ and it was pumped at the rated of 1litter/min. We used technique patch-closure with Interrupted Sutures or Continuous Sutures (pledget- supported) or Directly Sutures with no patch.

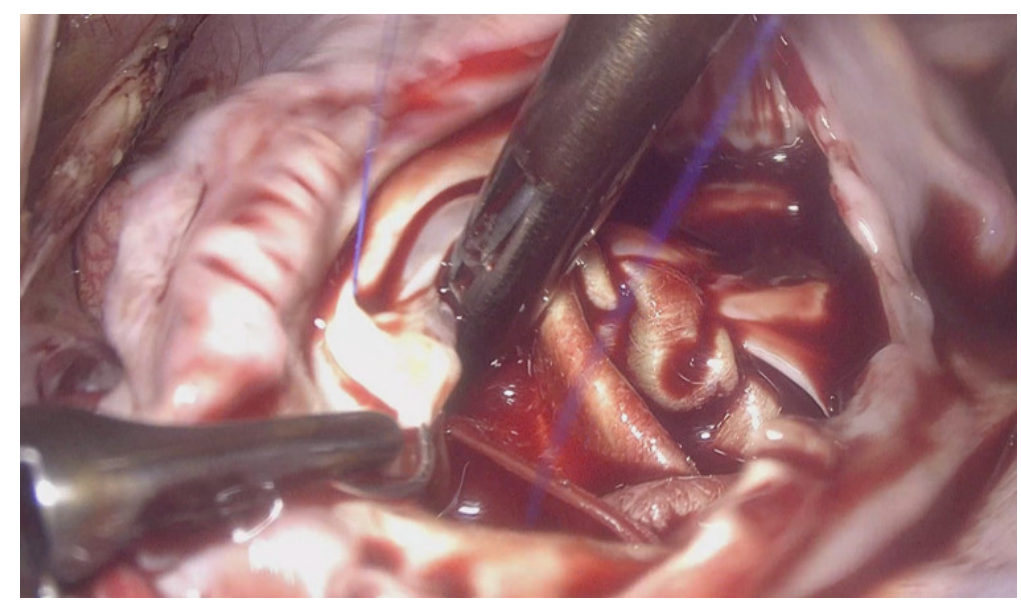

Figure 3: ASD patch close

After finishing closure, we closed the right atrial and checked for bleeding. We put one drainage of the right pleural cavity and all the procedures on beating heats.

\section{RESULTS}

All patients had successfuly surgery by total endoscopic with three trocarts. There were 8 ostium secundum ASDs, 1 coronary sinus ASD and 3 sinus venosus ASDs. The diameter of right ventricle was 1.6 times lager than the Body Surface Area (BSA) standard index of the right ventricle.

Table 1: Patient's clinical data

\begin{tabular}{|c|c|}
\hline Variable & Value \\
\hline Patient & 12 \\
\hline Male & 4 \\
\hline Female & 8 \\
\hline Age (y) & $7,7(2,5-11)$ \\
\hline Weight (kg) & $20,8(12-40)$ \\
\hline Ostium Secundum ASD & 8 \\
\hline Coronary Sinus ASD & 1 \\
\hline Sinus Venosus ASD & 3 \\
\hline $\begin{array}{l}\text { The mean peripheral circulation time was } 70 \\
\text { nutes ( range from } 56 \text { to } 100 \text { minutes) on beating } \\
\text { irts. There were } 8 \text { cases with patch-closure and } 4 \\
\text { es with direct-closure. The mean mechanical } \\
\text { tilation time was } 12 \text { hours No mortality and }\end{array}$ & $\begin{array}{l}\text { complication. After operations, we checked by } \\
\text { echocardiography, full of atrial septal defects were } \\
\text { closed with no residual shunt, the common femoral } \\
\text { arteries at the canula position were normal and not } \\
\text { stenosis. Patient discharged post operation } 6.3 \text { days. }\end{array}$ \\
\hline
\end{tabular}




\section{DISCUSSION}

The minimally invasive cardiac surgery includes surgery that do not completely open the sternum such as partial sternotomy, right thoracotomy, assisted endoscopic surgery, and total endoscopic surgery $\left[\begin{array}{ll}4 & -5\end{array}\right]$. The total endoscopic cardiac surgery has been performed routinely at cardiovascular center, E Hospital. In the first term, we did through 4 trocars, then, we reduced to 3 trocars. One of the difficulties of minimally invasive cardiac surgery in children was setting peripheral cardiopulmonary bypass. Due to low weight, the diameter of common femoral artery and femoral vein were smaller. Therefore, the risk of postoperative stenosis was high. So, for patients weighing more than $20 \mathrm{~kg}$, we put a cannula into common femoral artery through a size 8 unigraft artificial vessel. And for patients weighing less than $20 \mathrm{~kg}$, we actively placed 2 cannula in both sides with diameter of cannula smaller than the diameter of common femoral artery. This helps to avoid injury to the common femoral artery and still maintains adequate artery flow and pressure below 220mmHg. Superior vena cava (SVC) and inferior vena cava (IVC) cannula were placed through the right IJV and femoral vein. With CO2 in the surgical field, they had the effect of pushing other air out because the specific gravity of $\mathrm{CO} 2$ is heavier than other air and $\mathrm{C} 02$ was soluble in the blood so it did not cause air embolism complications [6].

One of other dificulties was that there was a lot of blood in surgical field. So we had to dissect SVC from right pulmonary artery and snaring SVC[5]. In addition, we could lower the temperature to 34 degree Celsius and lower circulating flow. Totally endoscopic cardiac surgery for ASD closure on beating heart is safe, with short recovery period, and high cosmetic value, especially in women.

For this surgery, the duration of mechanical ventilation was shot and the hospital stay was not long. The patient could be active soon. The postoperative echocardiography investigation, the ASD was full closed with no residual shunt, and there was no stenosis of common femoral artery and vein. Patients returned to normal life soon.

Conclusion: Totally endoscopic closure for ASD on beating hearts with 3 trocars is save with a very good short-term results.

\section{REFERENCE}

1. Seth s. Martin, Edward P. Shapiro and Monica Mukherjee (2014): Atrial Septal Defects - Clinical Manifestations, Echo Assessment, and Intervention Cardiology :8(s1) 93-98

2. Tal Geva, Jose D Martins, Rachel M Wald (2014): Atrial septal defects. Lancet ; 383: 1921-32

3. LAWRENCE H. COHN, ANDREW G. MORROW, AND EUGENE BRAUNWALD (1967): Operative Treatment of Atrial Septal Defect: Clinical and Hamodynamic Assessments in 175Patients. Brit Heart Journal, 29, 725

4. Elbeery JR el al (1997): Minimally invasive cardiac surgery. Heart surgery for the 21 st century. NC Med J. 58(5), 374-7

5. Yihu Tang, Yanhu Wu, Jinfu Zhu, Xiang Liu, Jinxin Zhou (2018): Total endoscopic repair of atrial septal defect under on-pump beating heart J Thorac Dis;10(12):6557-6562.

6. Ma ZS, Dong MF et al (2012): Totally thoracscopic closure for atrial septal defect on perfused beating hearts. Eur $J$ Cardiothorac Surg.41:1316-9. 